\title{
Proceeding
}

\section{Successful tactics in taekwondo during Sukan Malaysia 2012}

\author{
SITI FUZYMA AYU MOHD KASSIM1 ${ }^{1}$, EDIN KARDIN SUWARGANDA ${ }^{1}$, EMY NOR ASMIEZA MOHD NOR² \\ ${ }^{1}$ Centre for Biomechanics, National Sports Institute of Malaysia, Malaysia \\ ${ }^{2}$ Research Education and Sports Innovation and Division, National Sports Institute of Malaysia, Malaysia
}

\begin{abstract}
Mohd Kassim, S.F., Suwarganda, E., Mohd Nor, E. (2015). Successful tactics in Taekwondo during Sukan Malaysia 2012. J. Hum. Sport Exerc., 9(Proc2), pp.S723-S730. Introduction: The aim of the present study was to analyse the tactics performed by winner and non-winner during Sukan Malaysia (SUKMA) 2012. At present, scientific information and notational analysis on tactical aspects by Malaysia's taekwondo youth is non-existent. Methods: Sixty two male taekwondo athletes were included in this study. Video recording was taken of 55 matches from quarter final to final involving four weight categories $(<58 \mathrm{~kg}, 58-68 \mathrm{~kg}$, $68-80 \mathrm{~kg}$ and $>80 \mathrm{~kg}$ ). Notational analysis for all matches was done using SportsCode Pro 8.5.2. The variables coded were tactics (attack and defence), techniques, target area and point result. The total number of attempts and successful attempts were counted per category for winner and non-winner. Chi-square statistical method was used to compare the total number of successful attempts between winner and non-winner for each tactic. Results: The Chi-square result shows no significant difference between winners and non-winners for tactics used across all weight categories and matches for total successful attempts $(x 2=4.00, d f=3, p<0.05)$, for successful attacks $(x 2=5.50, d f=3, p<0.05)$ and for successful defence $(x 2=1.97, d f=3$, $p<0.05$ ). Winners have 343 total (attack and defence) successful attempts, out of that 192 for attacking and 151 for defending. Non-winner received 172 total (attack and defence) successful attempts with 116 for attacking and 56 for defending. Winners however, have higher percentage of successfulness in attack and defence compared to non-winners. From 2187 total attempts, winners' successfulness is $9 \%$ for attack and $7 \%$ for defence. Non-winners have 2352 total attempts, achieving $5 \%$ successfulness for attack and $2 \%$ for defence. Discussion \& Conclusion: The result shows no differences in tactics for both winner and non-winner. Even though non-winners attempt more than winners (total: 2352 vs 2187, attacking attempt: 1749 vs 1391 and defensive attempt: 603 vs 796), winners have higher successfulness in attacking and defensive tactics. Possibly, winners have a qualitative difference that could explain the higher percentage of successfulness in attacking and defensive tactics compared to non-winners. Further investigation should be done in the sequence and quality of attempts to understand more about successfulness of attempts in Malaysian taekwondo youth. Key words: TAEKWONDO, TECHNIQUES, SUCCESFUL ATTEMPTS, TACTICS.
\end{abstract}

Corresponding author. Centre for Biomechanics, National Sports Institute of Malaysia, Malaysia.

Asia Pacific Conference on Performance Analysis of Sport, 21-24 April 2014. Langkawi, Malaysia.

JOURNAL OF HUMAN SPORT \& EXERCISE ISSN 1988-5202

(c) Faculty of Education. University of Alicante

doi:10.14198/jhse.2015.10.Proc2.12 


\section{INTRODUCTION}

Taekwondo has been introduced since 1960s in Malaysia and became one of the major event in Sukan Malaysia (SUKMA). The sparring consists of 3 rounds with 2 minutes each round and 1 minute intervals rest in each round. The permitted areas are trunk and head area. Points are given only when a kick is successful contact with an allowed body region. Valid points are divided in: one (1) point : for a valid attack on trunk protector, two (2) points for a valid turning kick to the trunk protector (depending on type of kick), three (3) points for a valid attack to the head and four (4) points for a valid kick to the head involving spinning kick (WTF).

Combination of movement and technique during sparring may vary. Scoring points can be from attacking and also from defending. Attacking tactics can be defined by executing attacks from an initial forward movement while attacks executed from a counter movement (as a reaction to an initial attack) will be defined as defensive tactics. Tornello, Capranica, Minganti, Chiodo, Condello \& Tessitore (2014) stated that winners show more efficient for both technique and tactical variables. However, for tactics used during the match, winners were more successful in offensive strategies (Tornello et al., 2014; Kazemi, Waalen, Morgan \& White, 2006). Casolino, Lupo, Cortis, Chiodo, Minganti, Capranica \& Tessitore (2012) found in her research that youth athletes were found to use more offensive tactics than defensive tactics from the first round and significant decreased in second and third round. Most other studies (Falco, Landeo, Menescardi, Bermejo \& Estevan, 2012; Kwok, 2012; Luk, Hong \& Chu, 2001) were done on scoring and technical performance, e.g. types of kicks used but hardly on the tactics used during the match.

At present, scientific information and notational analysis of technical and tactical aspects during SUKMA on Malaysia youth athletes is non-existent. Thus, the objective of this study was to analyse the tactics (attack and defence) performed by winner and non-winner during Sukan Malaysia (SUKMA) 2012. A notational analysis will be used to analyse the match from quarter final one until final match in male category. Areas of interest in this study are tactics (attack and defence), target area and type of kick in winners and nonwinners. It has been hypothesized that the winner will use more defensive strategy. Hence, it is hoped that this findings will be useful in providing an insight to coaches.

\section{METHODOLOGY}

The data were taken during a SUKMA 2012 competition starting from quarter final one to final match. All matches of male from four main categories were involved in this study, which were Flyweight $(<58 \mathrm{~kg})$, Featherweight $(58-68 \mathrm{~kg})$, Welterweight $(68-80 \mathrm{~kg})$ and Heavyweight $(>80 \mathrm{~kg})$. Each match consists of 3 rounds with 2 minutes per round and 1 minute interval rest in each round. The matches were recorded using two Sony hard disk cameras. Both cameras were panning following the taekwondo players throughout the entire match. One camera was placed level with the player and the other camera was placed at higher level so players' movement can be seen from above. A notational analysis was done for a total of 54 matches using SportsCode Pro 8.5.2. Winners and non-winners of each match were coded at the same time. The match was coded for following category of variables; strategy (effective attacking and defending strategies and total effective movement attempts), type of kicks (turning kick, chopping kick, back kick, double turning kick, reverse swing kick, side kick and pushing kick) and target area (head, trunk and side). A Chi-square analysis method was used to compare the total number of successful attempts and total attempts in attacking and defending between winners and non-winners across all weight categories. Statistical significance was set at $p \leq 0.05$. 


\section{RESULTS}

This study analysed the total numbers of attempt and the successful attempt. Additionally, target area and type of kicking were analysed. Using a Chi-square statistical analysis revealed there was no significant differences in total successful attempts $\left(x^{2}=4.00, d f=3, p<0.05\right)$, successful attacks $\left(x^{2}=5.50, d f=3, p<0.05\right)$ and successful defence $\left(x^{2}=1.97, d f=3, p<0.05\right)$ across all weight categories.

Table 1. Numbers of attempt in total movement and successful tactics between winners and non-winners across all weight categories

\begin{tabular}{lcccc}
\hline & \multicolumn{2}{c}{ Winners } & \multicolumn{2}{c}{ Non-Winners } \\
\hline & $\begin{array}{c}\text { Total } \\
\text { Attempt } \\
(\mathrm{Nr})\end{array}$ & $\begin{array}{c}\text { Successful } \\
\text { Attempt }\end{array}$ & $\begin{array}{c}\text { Total } \\
\text { Attempt } \\
(\mathrm{Nr})\end{array}$ & $\begin{array}{c}\text { Successful } \\
\text { Attempt }\end{array}$ \\
& 1391 & 192 & 1749 & $(\mathrm{Nr})$ \\
Attack & 796 & 151 & 116 & 56 \\
Defence & 2187 & 343 & 2352 & 172 \\
Total & & & & \\
\hline
\end{tabular}

Referring to table 1 , it shows that in overall the total numbers of attempt winners have lesser number compared to non-winner (2187 vs 2352) with difference of 165 . Featherweight category has biggest difference number in total movement than non-winner with 70 (534 vs 604). Meanwhile, Finweight and Welterweight category have more similar differences in number of movements (Finweight category: 539 vs 581 and Welterweight category: 475 vs 517 ). However, Heavyweight category has relatively small differences of 11 (639 vs 650) compared to other categories. Overall, winners performed only 2187 numbers in total attempt and from this total attempt winners' successfulness for attacking tactics is $9 \%$ and $7 \%$ for defending tactics. Whereas out of 2352 numbers of total attempts, non-winners achieving $5 \%$ successfulness from attacking tactics and $2 \%$ for defending tactics.

Referred to table 1 above, winners achieved 343 numbers of successful tactics consisting of 192 from attacking tactics and 151 from defending tactics. Non-winners, achieved 172 from total successful attampts with 116 from attacking tactics and 56 from defending tactics. Out of the 172 attempts, 54 came from in Featherweight category, followed by Heavyweight category with 49 and Welterweight category with 44 and Finweight category with only 24 .

Table 2. Percentage of successful movements performed by winners and non-winner in attacking and defending tactics

Movement Winners $\quad$ Non-winners

$(\%)$

(\%) 


\begin{tabular}{clcc}
\hline $\begin{array}{c}\text { Attacking } \\
\text { Tactics }\end{array}$ & Forward & 24 & 34 \\
& Sliding Forward & 9 & 9 \\
& Shuffle & 0 & 1 \\
& Still & 22 & 22 \\
& Sideway & 0 & 1 \\
& Backward & 7 & 5 \\
& Sliding Backward & 10 & 5 \\
Defending & Shuffle & 1 & 2 \\
& Still & 24 & 19 \\
& Sideway & 2 & 2 \\
\hline
\end{tabular}

The successful of tactics between winners and non-winners can be seen in table 2. In the table, it describes the successful movements in attacking tactics and defending tactics performed across all weight categories based on total successful numbers of movements. For attacking tactics, winners and non-winners have not much different in percentage except non-winners were more successful in forward movement with $10 \%$ difference from winners. However, in defending tactics, winners have better percentage than non-winners. The difference in percentage from non-winners can be seen in backward (2\%), sliding backward (5\%) and still movements (5\%). Winners were successful in both tactics, but was more successful in defending tactics compared to non-winners. Winners achieved $9 \%$ of successful tactics in attack from the total number of movement and $7 \%$ from successful defending tactics. Non-winners were successful in attacking tactics, but not in defending tactics by achieving $5 \%$ in attack and $2 \%$ from defending tactics from total number of movements.

Table 3. Percentage of successful target area between winners and nonwinners

\begin{tabular}{lcc}
\hline Area & $\begin{array}{c}\text { Winner } \\
(\%)\end{array}$ & $\begin{array}{c}\text { Non-winner } \\
(\%)\end{array}$ \\
\hline Trunk & 31 & 33 \\
Side & 48 & 51 \\
Head & 22 & 16 \\
\hline
\end{tabular}


Table 4. Percentage of successful type of kicking performed by winners and non-winner

\begin{tabular}{lcc}
\hline Type of kicks & $\begin{array}{c}\text { Winner } \\
(\%)\end{array}$ & $\begin{array}{c}\text { Non-winner } \\
(\%)\end{array}$ \\
\hline Turning Kick & 65 & 72 \\
Chopping Kick & 17 & 12 \\
Side Kick & 4 & 3 \\
Double Turning Kick & 7 & 7 \\
Back Kick & 3 & 3 \\
Pushing Kick & 1 & 2 \\
Reverse Swing Kick & 2 & 1 \\
\hline
\end{tabular}

Table 3 and table 4 show the percentages of target area and the type of kick that contributed to scoring. The percentages in table 3 show that non-winners have better scoring percentage at trunk and side areas compared to winners, but winners scored more at the head area with $6 \%$ difference from non-winners. Table 4 revealed that the main type of kicking that contributed to points for winners were turning kick (65\%), chopping kick (17\%), double turning kick (7\%). The other types of kicking also contributed to points, but were considered not the main contribution. Non-winners have the same pattern of percentage as winners by having turning kick with $72 \%$ as a main contributing factor, followed by chopping kick $(12 \%)$ and double turning kick (7\%). Even though winners and non-winners have the same type of kicking that contributed to points, by linking the table 3 and table 4 we can see that winners scored more at the head area with chopping kick. This could be a major contributor to win.

\section{DISCUSSION}

The purpose of this study was to see the tactics performed by winners and non-winners. In this study, statistic analysis showed no significant result was found in successful tactics (attacking, defending and both) between winner and non-winner. Even though non-winners attempt more than winners (total: 2352 vs 2187; attacking attempt: 1749 vs 1391 and defensive attempt: 603 vs 796), winners have higher successfulness in attacking and defensive tactics. Result in Table 1 represent a total number of movements that shows winners have more effective tactics compared to non-winner. With total attempts of 2187 executed in the tactics, winners achieved 193 for attacking and 150 for defending in successful attempts, while non-winners only achieved successful of 116 for attacking and 56 for defending out of 2352 in total attempts. This number shows that winners have lower number of movements but higher success in scoring as compared to non-winners. This indicates that winners have more successful tactics used during the match. By comparing the data in table 2, the percentage in tactics performed by winners and non-winners reveal that winners were more successful in defending tactics and non-winners were successful in attacking tactics. Winners succeed in defending tactics because non-winners executed more in attacking 
which allowing winners to use defending tactics. This is contrary to Tornello et al., (2014) \& Kazemi et al., (2006), whom found winners were more successful in offensive strategies.

But what makes winners win may also be related to target area and technique used during the match. According to Falco et al., (2012), a kick to the head together with a spinning movement will maximise the points scoring based on new taekwondo competition rules. The result of scoring areas can be found in table 3. The table showed winners and non-winners have no differences in percentage at the trunk and side area which were relatively low with $2 \%$ to $3 \%$ difference. However, winners achieved $10 \%$ more than non-winner in getting points at the head area. Therefore, winners achieved more points by attacking at the head area, which ultimately makes the area was more successful in scoring as compared to non-winners, as non-winners were more keen to score at the side and trunk areas than the head area. Attacking at permitted area at body only allowed maximum of 1 or 2 points for each successful kick. However, if the kick was a successful hit at the head area, the points given are 3 points and sometimes be up to 4 points depending whether there was a spinning movement involved in the kick. As a strategy, more points can be achieved by applying a kick to the head with or without any spinning movement.

A successful kick to the head can be linked to table 4 which type of kicking is presented in the table. Type of kicking that targeting the head area were chopping kick and reverse swing kick. Winners achieved 5\% more in chopping kick (17\% vs $12 \%)$ and $1 \%$ more in reverse swing kick ( $2 \%$ vs $1 \%)$ than non-winners. Non-winners were more successful in turning kick by achieving $7 \%$ more than winners (65\% vs $72 \%)$. Even though non-winners performed much more in turning kick, it does not contribute much in points scoring as the target area were trunk and side area. These two areas were only contributed to 1 or 2 points. Winners performed better in chopping kick and reverse swing kick in which, these kicks were targeting the head area. Since the points given to the head consists of 3 or 4 points, winners successful utilised it by performing chopping kick and reverse swing kick to the head. Therefore, by applying such tactics allowed winners to gain points and win the match (Kwok, 2012). This was supported by Mori et al., (2002) that stated in his study that in winning a result of the match can be linked to the area of attacking, that the technique used at the most points area.

Possibly, winners have a qualitative difference that could explain the higher percentage of successfulness in attacking and defensive tactics compared to non -winners. Few studies have been done for match analysis in martial art. The studies found that tactics were used by non-winners during the match was an attacking movements, hence it allowed winners to anticipate and prepare with defence strategies (Asia et al., 2013; Tornello et al., 2014; Kazemi et al., 2006). In taekwondo, attacking and defending tactics are two important strategies that need to be decided by taekwondo players during the match. Apart from the strategies used or the techniques executed, it is crucial enough to anticipate the movement of the opponent so the winner may be able to move or to react towards the action performs by the opponent (Mori, Ohtani \& Imanaka, 2002; Brito \& Silva, 2011).

Since there is no significant difference between winners and non-winners, it is believed that winners made better decision making during scoring the points. When it comes to a critical situation where a decision has to be made precisely, one should make the right decision at that moment. Shorter reaction time will be beneficial to the players as it helps them to anticipate and score better (Asia \& Warkar, 2013; Mori et al., 2002; Brito \& Silva, 2011). This explains why winners have a higher percentage in defending tactics compared to non-winners because it allows winners to anticipate non-winners tactics and later will decide what technique, tactics and area of scoring should be used (Borysiuk, 2008). Winners have to react fast which required shorter reaction time (Asia et al., 2013) and response to the decision from the reaction in 
which articulation of neurosensory and neuromotor adaptations are involved during this process (Brito \& Silva, 2011). This could be another explanation why winners win even since there is no significant difference in total number of movement and successful in tactics.

However, in this study the subjects' age, level of experience, technical performance, training duration represent the delimitations of this study. It is believed that this kind of data can provide more details in future research.

\section{CONCLUSIONS}

This study reveals that winners have more efficient tactics (attack and defence) compared to non-winners. This result is supported by Tornella et at., (2014) \& Kazemi et al., (2006) in which winners have greater efficiency in tactical and technical and winners show higher defensive mode than offensive mode. Together with the types of kick used and targeting area during the matches allowed winners achieve higher points with lesser attempts. Although there is no significant difference between winners and non-winners, winners possibly have a qualitative difference that could explain the slightly higher percentage of successfulness in attacking and defensive tactics compared to non-winners. It is highly believed that experts are better in anticipating opponents' tactics and have an ability to react or respond quickly to the tactics performed by the opponents (Asia et al., 2013; Mori et al., 2002; Brito \& Silva, 2011; Borysiuk, 2008). Therefore, despite of training the athlete in strategies and technique, it is highly recommended to train the athlete in anticipating the opponent's movement as well. This would help the athlete to identify the tactics perform by the opponent and therefore would help the athlete to execute the right technique in order to achieve points. Further investigation should be done in the sequence and quality of attempts to understand more about the successfulness of attempts in Malaysian taekwondo youth.

\section{ACKNOWLEDGEMENT}

We would like to thank all the staffs of National Sports Institute of Malaysia that involved in collecting the data.

\section{REFERENCES}

1. Asia, A.A. \& Warkar, A.B. (2013). Auditory and visual reaction time in Taekwondo players. Borsyiuk, Z. (2008). The significance of sensorimotor response components and EMG signals depending on stimuli type in fencing. Acta Univ. Palacki Olomuc, 38(1), pp.43-51.

2. Brito, A.V. \& Silva, C. (2011). Reaction Time in Karate Athletes. Journal of Martial Arts Anthropology, 11(4), pp.35-39.

3. Casolino, E., Lupo, C., Cortis, C., Chiodo, S., Minganti, C., Capranica, L. \& Tessitore, A. (2012) Technical and tactical analysis of youth Taekwondo performance. Journal of strength \& conditioning research, 26(6), pp.1489-1495.

4. Falco, C., Landeo, R., Menescardi, C., Bermejo, J.L. \& Estevan, I. (2012). Match analysis in the University Taekwondo Championship. Advances in Physical Education, 2(1), pp.28-31.

5. Internation Journal of Recent Trends in Science and Technology, 8(3), pp.176-177.

6. Kazemi, M., Waalen, J., Morgan, C. \& White, A.R. (2006). A Profile of Olympic Taekwondo Competitors. Journal of Sports Science and Medicine, 5(CSSI), pp.114-121.

7. Kwok, H.H.M. (2012). Discepancies in fighting strategies between Taekwondo medalists and nonmedalists. Journal of Human Sport and Exercise, 7(4), pp.806-814. 
8. Luk, T.C., Hong, Y. \& Chu, D.P.K. (2001). Analysis of strategy used in Taekwondo competition. Biomechanics Symposia, University of San Francisco, The United States of America.

9. Mori, S., Ohtani, Y. \& Imanaka, K. (2002). Reaction times and anticipating skills of karate athletes. Human Movement Science, 21(2), pp.213-230.

10. Tornello, F., Capranica, L., Minganti, C., Chiodo, S., Condello, G.C. \& Tessitore, A. (2014). Technical-tactical analysis of youth Olympic Taekwondo combat. Journal of Strength \& Conditioning Research, 28(4), pp.1151-1157.

11. World Taekwondo Federation (2013) Valid point. URL (last checked July 14, 2013). http://worldtaekwondofederation.net/images/Competition_Rules_2013-07-14_Puebla_GA.pdf 